\title{
PSA Level Less than Five
}

National Cancer Institute

\section{Source}

National Cancer Institute. PSA Level Less than Five. NCI Thesaurus. Code C124828.

A blood concentration of prostate specific antigen below $5 \mathrm{ng} / \mathrm{mL}$. 